\title{
Assessing North Atlantic Right Whale (Eubalaena glacialis) Welfare
}

\author{
Katherine King ${ }^{1, *}$, Melissa Joblon ${ }^{2}$, Kerry McNally ${ }^{2} \mathbb{D}$, Leigh Clayton ${ }^{2}$, Heather Pettis ${ }^{3}$, Peter Corkeron ${ }^{3}$ \\ and Felicia Nutter 4 \\ 1 Cummings School of Veterinary Medicine, Tufts University, Grafton, MA 01536, USA \\ 2 Animal Care Division, New England Aquarium, Boston, MA 02110, USA; mjoblon@neaq.org (M.J.); \\ kmcnally@cmaquarium.org (K.M.); lclayton@neaq.org (L.C.) \\ 3 Anderson Cabot Center for Ocean Life, New England Aquarium, Boston, MA 02110, USA; \\ hpettis@neaq.org (H.P.); pcorkeron@neaq.org (P.C.) \\ 4 Department of Infectious Disease and Global Health, Cummings School of Veterinary Medicine, \\ Tufts University, Grafton, MA 01536, USA; felicia.nutter@tufts.edu \\ * Correspondence: katherine_j.king@tufts.edu
}

check for updates

Citation: King, K.; Joblon, M.; McNally, K.; Clayton, L.; Pettis, H.; Corkeron, P.; Nutter, F. Assessing North Atlantic Right Whale (Eubalaena glacialis) Welfare. J. Zool. Bot. Gard. 2021, 2, 728-739. https:// doi.org/10.3390/jzbg2040052

Academic Editor: Lance Miller

Received: 13 September 2021 Accepted: 10 December 2021 Published: 17 December 2021

Publisher's Note: MDPI stays neutral with regard to jurisdictional claims in published maps and institutional affiliations.

Copyright: (c) 2021 by the authors. Licensee MDPI, Basel, Switzerland. This article is an open access article distributed under the terms and conditions of the Creative Commons Attribution (CC BY) license (https:// creativecommons.org/licenses/by/ $4.0 /)$.

\begin{abstract}
Welfare assessments have been largely successful in improving management and quality of life for animals in human care. This has prompted an increased interest in their use for freeranging wild animals to assess health, environment, and human-induced impacts that influence policy decisions. The North Atlantic Right Whale (NARW, Eubalaena glacialis) is one of the most endangered whale species. NARWs constantly face serious injuries and mortalities due to human activities, which poses both a species conservation and an individual welfare concern. Establishing a standardized welfare assessment for the NARW is a holistic way to understand the cumulative effects of anthropogenic activities at both the individual and population levels. To investigate the potential use of welfare assessments in NARWs, we performed a brief literature review to explore the history and utility of animal welfare assessments. Following the review, we developed a welfare assessment tool specific to the NARW. The goal is for biologists to apply this tool to understand NARW welfare in conjunction with research in the field. Ultimately, the information gained from this review can aid in public dissemination of the results of human impacts on NARW welfare and may help influence future conservation policies.
\end{abstract}

Keywords: North Atlantic right whale; animal welfare; conservation; animal welfare assessments

\section{The Plight of the North Atlantic Right Whale as a Welfare Concern}

The North Atlantic right whale (NARW, Eubalaena glacialis) is one of the most endangered large whale species and is listed as Critically Endangered by the International Union for the Conservation of Nature (IUCN) [1]. As of the end of 2019, the population estimate was 356 individuals, a decline of approximately $25 \%$ from their peak abundance in 2010 [2,3]. Individual NARWs incur serious injuries and death due to human-induced effects on their ocean habitat [4]. For the 43 individuals that were known to have died between 2003 and 2018, and for which the cause of death was identified, 88.4\% were attributed to human activities (entanglement in fishing gear and vessel strikes) [5]. Not only are these unintentional NARW deaths a substantial conservation concern for this declining population, but how entangled animals die is a significant animal welfare concern [6]. To explore the relationship between animal welfare and conservation science, this paper will examine welfare assessments created for non-domestic species with the goal of creating a welfare assessment for NARW.

A slow death is common for entangled large whales. Moore et al. reported that an entangled NARW suffers for an average of 5.6 months from detection to death, an underestimation of total entanglement time because of delays in detection [6]. An estimated 
$83 \%$ of NARWs have been entangled at least once, and approximately $60 \%$ of individuals show evidence of multiple entanglements [7]. The methods by which NARWs can succumb to gear entanglement include drowning due to inability to surface; starvation caused by gear wrapped around the head, the rostrum and around the baleen interfering with feeding; increased energy expenditure due to increased drag from towing gear; and tissue damage and infection from gear-related trauma [8]. Entanglement in fishing gear is an inhumane way to die and causes a welfare concern in addition to the conservation threat for the NARWs [9].

Shipping traffic has increased steadily since 1950 and NARWs, due to their preferred habitat, are at two orders of magnitude more likely to be struck by vessels compared to other large whales [10]. From 1970-2006, more than half of the NARW deaths were attributed to vessel strikes [11]. More recently, in 2020, one of the two deaths was due to a vessel striking a calf and there were three non-lethal vessel strikes [12]. Ship strikes cause blunt trauma from the ship's hull (e.g., fractures and internal hemorrhage), sharp trauma from the ship's propellors (often causing wounds and lacerations), or a combination of both [13]. Not all NARWs struck by ships die immediately. Many suffer due to their injuries and die after prolonged periods from the cumulative effects of tissue damage, infection, and starvation [13].

Ocean noise pollution from human activities, including commercial shipping, recreation, military activity, and offshore oil and gas exploration, has also increased dramatically in recent decades [14]. The coastal and continental shelf regions that have seen the greatest increases in both background noise and peak intensity sound are core NARW habitat [14]. As NARWs are a highly social species and rely heavily on social communication, the increased ocean noise has forced NARWs to increase the amplitude of their calls to be heard by their conspecifics [15]. Increased ocean noise is also correlated with increased fecal cortisol levels, which are an indicator of stress [16].

The effects of global climate change also impact the survival of the NARWs. NARWs feed almost exclusively on Calanus finmarchicus, a zooplankton species with an optimal temperature range of $4.5-8.5^{\circ} \mathrm{C}$ [17]. Rapidly warming deep water along the Scotian Shelf has decreased abundance and shifted the range of $C$. finmarchicus northward $[17,18]$. The northward shift of this main prey source appears to have also driven NARWs northward $[18,19]$. This change in foraging habitat has been correlated with decreased reproduction and increased mortality from vessel strikes and gear entanglement [20].

As a result of these conservation concerns, many tools have been developed to better understand the stressors of large whales [21]. These tools range from observational assessments of body condition, skin condition, and presence of scars to sampling and analyzing fecal material, respiratory vapor, or skin [1,21,22]. Fecal and respiratory vapor samples provide information on reproductive status, stress hormones, biotoxins, microbial communities, immunity, and nutritional status [1]. Biopsies of skin and blubber contribute additional information on endocrine status, microbiome, immune function, and toxin levels of large whales [21]. Observational analysis of growth, body condition, skin condition and wounds by aerial photogrammetry is useful in assessing individual and population health [1] and determining changes in whales' growth rates over time [23]. Baleen has been used to gain a multi-year profile of cortisol levels in NARWs to evaluate stress and determine reproductive status [24]. Location and movement information are gained from passive acoustic data [25], mark-recapture using photo-identification data [2], or necropsies [1]. While these tools provide valuable information about the health and conservation status of the NARW, a more integrative approach to assessing health and general well-being by incorporating animal welfare assessments will complement existing knowledge.

\section{The History of and Relationship between Animal Welfare and Conservation Science}

Definitions of animal welfare science have circulated since 1965 when WH Thorpe first defined it as the study of veterinary concerns, such as disease and injury, as they interact with physiological indicators of stress, the change in behavior with pain and discomfort, 
motivation in confinement, and environmental preferences [26]. Since then, a broader definition of animal welfare science has been adopted to include everything about an animal's condition as it lives in its habitat [27]. Animal welfare science serves to answer the following three questions: (1) are animals conscious?, (2) how can we assess positive vs. negative welfare in animals?, and (3) how can science improve animal welfare? [18].

In 1964, "Animal Machines" was published, which argued that livestock in the production industry were treated like inanimate machines, prompting the formation of the Brambell Committee in the United Kingdom [27]. The resulting Brambell Report identified a list of basic freedoms for animals. This list was officially identified as the Five Freedoms by John Webster in 1993 and comprised of the freedom from thirst, hunger and malnutrition; the freedom from discomfort and exposure; the freedom from pain, injury and disease; the freedom from fear and distress; and the freedom to express normal behavior [28]. Over time, animal welfare science moved away from preventing negative experiences to promoting positive experiences by incorporating an animal's mental state [28]. From this, The Five Domains Model (FDM) was developed by Mellor and Reid in 1994 [29]. FDM considers animal welfare as a combination of four domains based on biological function (nutrition, environment, health and behavior) and a fifth domain which focuses on the mental state of the animal, or its "psychological well-being" [30].

Throughout its history, animal welfare science neglected to address the welfare of wild animals. Conservation science developed, in part, to address this gap and originated from the desire to prevent the extinction of species [26]. Conservation science specifically examines wild animals at the level of populations and ecosystems and addresses threats that affect biodiversity and the integrity of biological systems [26].

In contrast, animal welfare science predominantly focuses on individual animals and their day-to-day experiences. Conservation science assesses the health of the population as a whole, while welfare science focuses on assessing individual animals to gauge the health of the entire population [30]. These different approaches to assessing population health are a challenge to the synthesis of the two fields [30]. While it is difficult to apply both conservation science and animal welfare science to larger populations, it is more feasible to evaluate small populations, particularly threatened and endangered species, through both lenses [31,32]. The term "extreme conservation" has been defined as "efforts targeted to deliberately increase positive human influences, including the detection and veterinary treatment of potentially life-threatening conditions and close surveillance of individual animals" [33]. This practice of extreme conservation has been applied to the NARW through the efforts of several organizations that monitor individuals, document their behavior and health status, respond to health emergencies such as fishing gear entanglements, and collect data to analyze population status $[1,33]$.

The conversation about how an animal interacts with its environment and how human activities affect animals would not be complete without the discussion of stress. Coined by Hans Selye in relation to laboratory rats, stress incorporates all the physiological responses an animal has when it encounters conditions that are outside of its preferred state or outside of its equilibrium [34]. In the animal welfare science context, a stress response is how an animal responds to a negative change in its environment [27,34]. Wild animals experience increased levels of stress due to negative human impacts on their environments, such as chemical and noise pollution, habitat degradation, or hunting/trapping [34], which are also relevant to conservation science. Increased stress can decrease reproductive success, reduce immune function, and inhibit growth-all of which decrease the likelihood of survival of an individual and, ultimately, a population and species [35]. Chronic stress caused by human activities is an issue best addressed collaboratively by both animal welfare scientists and conservationists $[30,35,36]$. To incorporate animal welfare into conservation science, here we explore the use of animal welfare assessments for animals under human care and for free-ranging animals. 


\section{Welfare Assessments for Animals under Human Care}

Historically, animal welfare assessments focused mainly on livestock and laboratory animals [27]. The positive effects of such assessments on animal management policies have driven the use of animal welfare tools in zoo and aquaria settings. In 2015, the World Association of Zoos and Aquariums (WAZA) called on zoos and aquaria to prioritize high animal welfare standards for animals in their care; to be leaders, advocates, and advisors in animal welfare; and to ensure that all zoo and aquaria-housed animals have environments that exceed their behavioral and physical needs [37].

Since the animal welfare discussions within zoos and aquaria began, there have been challenges with how to adequately measure welfare in diverse species where biology and natural history differ greatly or are largely unknown [38]. An initial focus for animal welfare at zoos was on improving animal husbandry, including nutrition and enclosure design [39]. More recently, the welfare assessment strategies proposed for animals in zoos and aquaria not only focus on animal husbandry, but also apply both resource-based (what resources the animal has or is provided) and animal-based approaches (considers what the animal looks like physically, how it is behaving and its mental state) [40].

Several welfare assessment tools have been developed over the past decade for use with non-domestic species. Many of these tools target animals in zoos and aquaria for the ease of access. Each assessment tool has its strengths, weaknesses, and applicability for use in free-ranging wild animals; here we will review each and use them as tools to create an assessment for NARW.

\subsection{Zookeeper Ratings as an Animal Welfare Assessment Tool}

In 2009 , following the push by WAZA to incorporate animal welfare considerations into zoos and aquaria, many zoological institutions were interested in identifying methods to evaluate and improve animal welfare [41]. This often meant attempting to validate qualitative assessments to measure animal welfare. Researchers suggested that the daily assessments performed by zookeepers should be used to determine animal welfare through interpretation of the animals' behavior, posture, attitude, expression, and movement [41]. Institutions such as the Chicago Zoological Society, used the assessments to create a tool based on the animal-focused measures of welfare that the zookeepers recorded [41]. This meant that existing methods of assessment could be translated into basic welfare assessments. Similar to animals in zoos, individual NARWs are closely monitored in their natural habitat. These abundant field data could be utilized as part of a welfare assessment for these animals.

\subsection{The Detroit Zoological Society's Center for Zoo Animal Welfare (2015)}

The Detroit Zoological Society's Center for Zoo Animal Welfare was created to establish a framework for animal welfare assessments in zoological institutions to ensure the well-being of all animals at the individual and institutional levels [39]. The framework has four components: institutional philosophy and policy; program structure and available resources; execution; and evaluation [39]. Within the evaluation component, the Detroit Zoological Society proposed their individual animal welfare assessment tool. This tool is a series of closed-ended questions to which an evaluator can answer "yes", "somewhat", "no", "N/A" or "not clear" and then provide notes to support their answer. The questions ask the evaluator to consider an individual animal's environment, social groupings, behavior, nutrition, and enrichment in conjunction with the individual animal's autonomy over those different areas. Since 2015, the Center for Zoo Animal Welfare at the Detroit Zoological Society, now called the Center for Zoo and Aquarium Animal Welfare and Ethics, has been involved in many projects focusing on developing tools to help assess and improve welfare in zoo and aquarium animals.

This framework incorporates the importance of institutional policy and how it relates to animal welfare. As NARW are free-ranging, institutional policy does not relate to NARW. The evaluation component of the general framework could be applied to observing animals 
in the field and answering questions about their behavior, nutrition, social groupings, and environment. Although the results would provide some indication of welfare, they would not necessarily provide a clear categorization of positive or negative welfare that would be simple to communicate to both NARW scientists and the general public.

\subsection{An Animal Welfare Risk Assessment (2018)}

Similar to the tool designed by the Detroit Zoological Society's Center for Zoo Animal Welfare, Sherwen et al. developed an animal welfare risk assessment [40]. This assessment combined an institution-level assessment, individual animal monitoring tools, and direct research. The monitoring tool was based on the FDM [28] and included 20 different welfare indicators across the categories of environment (both physical and social), behavior, physical health/nutrition, and husbandry [40]. These indicators included both resourcebased and animal-based measures. The evaluators, predominantly keepers and those on animal care teams, scored the indicators from 0 (high risk or poor) to 2 (no risk or good). The use of a Likert scale to measure indicators allowed for a gradient that included moderate welfare or moderate risk instead of binary high risk/poor or no risk/good. The use of a numerical system also allowed researchers to score individual enclosures and an institution as a whole [40], and to better understand the process by which good welfare was achieved at the institutions they were studying. For the NARW, assigning numerical values to welfare indicators and developing scores for individuals would facilitate statistical analyses and comparisons between individuals and between different years.

\subsection{Animal Welfare Assessment Grid (AWAG) (2017)}

The Animal Welfare Assessment Grid (AWAG) [42] is another FDM-based welfare assessment tool, with four categories-physical, psychological, procedural, and environmental condition - that are scored from 1 to 10 with 1 being the gold standard. Scores are then plotted on a cruciform style grid with each category placed on a different arm of the grid [43]. This tool was originally developed for use in experimental primate research [44] and has been modified for use on primates and birds in zoological settings [42]. Under each category, there are criteria to help determine the welfare of individuals or groups of animals. To validate the modification for zoos, researchers scored the animals on a scale of 1 (best welfare) to 10 (worst welfare) in a 95-day trial period [42]. Using those scores, the researchers were able to compare the welfare of the animals throughout the trial period and against other individuals (primate-specific) in which the AWAG was being tested [42]. More recently, AWAG has been used on cattle and pigs in experimental settings. Researchers found that out of the four categories of AWAG, physical, procedural and environmental were straightforward to measure and they were able to successfully adapt AWAG for use in experimental cattle and pigs [43]. This flexibility and usefulness with a variety of species is a strength of AWAG and suggests that it might be useful when considering the welfare of NARWs.

The AWAG method expanded the numerical scale of Sherwen et al. from 3 to 10 and turned the scores into a visual representation of welfare. The addition of the graphical display of welfare scores by category is a powerful and potentially eye-catching method of sharing information with scientists and the general public. However, a graphic is less useful for comparing individuals and changes over time and in those situations the numerical values would be more useful in measuring NARW welfare.

\section{Welfare Assessment for Free-Ranging Wild Species}

With the development of animal welfare assessments for species under human care, conservation and animal welfare scientists were interested in incorporating welfare assessments into the conservation of free-ranging wild species. A literature review found that few welfare assessments for free-ranging wild species and most of these are performed using the FDM $[45,46]$. A significant barrier to more widespread implementation is the lack of a standardized, systematic approach to developing welfare assessments for individual 
species. To aid expert wildlife biologists and conservation scientists to incorporate welfare assessments in their work, a ten-step method for building a welfare assessment for any free-ranging wild species has been developed [46]. It guides users through the necessary types of knowledge needed to create a welfare assessment, such as how to identify indicators of welfare, and how to incorporate those indicators into the FDM [46]. This protocol would be beneficial in the development of new welfare assessments for species that lack established tools, such as free-ranging wild cetaceans, including the NARW.

\section{Welfare Assessments for Cetaceans}

There is a dearth of literature on animal welfare assessments for both cetaceans under human care and free-ranging wild cetaceans. Two methods currently available are the Cetacean Welfare Assessment (C-Well) and the Welfare Assessment Tool for Wild Cetaceans (WATWC) [47,48].

\subsection{C-Well}

C-Well was the first welfare assessment tool used specifically for marine mammals. It was developed by Clegg et al. to explore the welfare of common bottlenose dolphins (Tursiops truncatus) under human care [47]. C-Well is based on Welfare Quality ${ }^{\circledR}$, an animal welfare assessment tool for farm animals in the UK. Welfare Quality ${ }^{\circledR}$ evaluated welfare based on nutrition, housing, health, and appropriate behavior [47]. C-Well expanded upon the four categories of Welfare Quality ${ }^{\circledR}$, creating a framework with 11 criteria based on these categories and 36 measures to evaluate the criteria [47]. Each of the 36 measures is scored as 0, 1 or 2, with 0 being good welfare and 2 being poor welfare. Many of the criteria and measures in C-Well overlap to include redundancy so that no important welfare indicators are overlooked.

While many other welfare assessments use similar parameters and scoring methods to measure welfare, Clegg et al. used measures specific to marine mammals [47]. This provided an example of parameters that would be important to examine and include when developing a NARW-specific welfare assessment. As C-Well was designed for common bottlenose dolphins under human care, many parameters such as absence of pain associated with management procedures and criteria relating to the enclosures are not applicable to NARWs.

\subsection{The International Whaling Commission and the Welfare Assessment Tool for Wild Cetaceans (WATWC)}

Considering the focus on animal welfare in zoos and aquaria, the International Whaling Commission (IWC) developed a working group focused on the welfare of cetaceans impacted by human activity in the ocean [48]. The issues of special concern were non-hunting activities, including entanglement, ship strikes, whale watching, marine debris/litter, and habitat degradation and related matters [49]. In 2016, the working group reviewed the welfare threats to cetaceans and concluded that the FDM is applicable to evaluate free-ranging wild cetacean welfare [49]. The working group participants used a scale of 0 (no impact) to 2 (major impact) to score how both acute and chronic events affected cetacean welfare for four of the five domains. The environmental domain was left out, as it was deemed more relevant to cetaceans under human care [49].

The recommendation by the IWC working group to use the FDM for assessing freeranging wild cetacean welfare was further expanded by Nicol et al. (2020) with the Welfare Assessment Tool for Wild Cetaceans (WATWC) [48]. The WATWC focused on how a single event can affect free-ranging wild cetacean welfare. In comparison to the IWC model, the WATWC included all five domains, and added how long an event will affect the domains, event re-occurrence, and how the event will affect the lifespan of the animal [48]. The assessment also included a section where evaluators rated their confidence in their scoring. WATWC separated the objective and subjective measures of animal welfare while still emphasizing how physiological and environmental factors interact to produce different welfare states [48]. WATWC further supported the utility of the FDM for free-ranging 
cetaceans, such as the NARW, when the developers stated FDM is more useful for freeranging animals than either Welfare Quality ${ }^{\circledR}$ or the Five Freedoms.

\section{Introduction of the North Atlantic Right Whale Welfare Assessment Tool}

With the increasing threats to NARWs, welfare assessments should be included as a tool to better understand the overall condition and stressors affecting individuals. As the abilities to detect steroid and thyroid hormones in fecal matter and baleen have developed, there is more evidence to demonstrate that individual NARWs are subjected to substantial stress [49]. To further document the causes and degree of stress, we developed a prototypic NARW-specific welfare tool intended for use by field biologists to assess welfare in real time. The welfare scores can then be combined with other objective data such as stress hormone levels, reproductive status, biotoxin levels, and growth analysis to provide a more complete indication of the welfare status and overall health of the NARW individuals and population $[21,22,24,26]$.

\subsection{Development of a Prototypic NARW Welfare Assessment Tool}

As a result of the literature review, we identified several ways to structure animal welfare assessment tools. The two options we evaluated for free-ranging wild cetaceans were the FDM [28], which is the basis for many welfare assessment tools; and the Welfare Quality ${ }^{\circledR}$ framework, which is the basis for C-Well [47]. The C-Well and Welfare Quality ${ }^{\circledR}$ frameworks were designed for animals under human care and upon review were not easily adaptable to free-ranging wild cetaceans. Thus, we designed our welfare tool using the FDM framework because it provides a structure that is easily transferrable to freeranging wild species and has consistently proven to be a useful guide in measuring animal welfare [39].

It is difficult to accurately assess some of the categories of the FDM in free-ranging wild species. We included health and behavior data in the NARW assessment because they are routinely collected in a standardized, quantifiable manner by field researchers. The health section of the proposed NARW welfare assessment tool is based on the Visual Health Assessment developed by Pettis et al. (2004) [22]. This health assessment used photographs of NARWs taken by researchers to establish a health score based on skin condition (including the presence of wounds or scars), body condition, presence of rake marks, and presence of cyamids surrounding the blowholes [22]. The behavior section of the NARW welfare assessment was developed based on common behaviors, sighting observations, and environmental interactions defined in the North Atlantic Right Whale Consortium Photographic Database/Catalog Submission document [50]. We included behaviors or observations that were clearly defined or quantifiable (for example feeding, social interactions, swimming activity). We included specific environmental and human interactions in the behavioral section because they are also well-defined observations.

Environment, nutrition and mental state are difficult to measure for free-ranging wild species, particularly for marine mammals in the ocean environment. Although these categories have been considered in other welfare assessments, specific data are not always easy to interpret and include in a welfare assessment due to the variability of the natural environment of the NARW. Environmental variables such as water and air temperature, weather, presence of pollutants, and boat traffic change throughout the course of the day, and the effects of changes in these parameters on NARWs are not established. Mental state was designed to be inferred from the collection of data from the other categories [28]. Inference of mental state of the NARW is not currently possible, but with evolving research it may be possible to use cortisol, microbiota, or other physiologic measurements for this purpose. Future iterations of this assessment tool may be able to examine the feasibility of including specific welfare indicators pertaining to the environment and mental state and how they impact NARW health and welfare.

Nutrition was partially assessed through body condition score (BCS) and feeding behaviors. The addition of prey data, such as prey quality and abundance, was included 
to approximate the dietary records that are included in welfare assessments designed for animals under human care. As previously mentioned, climate driven ocean changes have led to alterations in feeding behaviors and reproduction in NARWs, in part due to decreased abundance and change in distribution of their primary zooplankton food source [18]. This decrease in prey abundance was considered similar to underfeeding an animal under human care, which would imply negative welfare. A method of counting plankton using an optical plankton counter (OPC) has been validated and could be used to estimate prey abundance as part of this assessment [51].

In addition to total food intake, prey quality is also an important measure of nutrition. NARWs not only specifically eat $C$. finmarchicus but they also prefer to consume the copepod when it is in Stage V of its life cycle [52]. During this stage, the copepod has a high lipid and total energy content $[52,53]$. Results of mathematical modeling suggest that for a region to be a suitable NARW feeding habitat the $C$. finmarchicus in the area need to provide a minimum energy density of $3 \mathrm{~kJ} / \mathrm{m}^{3}$ [53]. Measuring the energy content of NARW prey provides a key indicator of feed quality and therefore nutritional welfare, so this parameter was included in the prototypic tool presented here [51]. While these data may not be readily available when observing NARWs in the field, there are several plankton monitoring programs such as Atlantic Zone Monitoring Program (AZMP), Continuous Plankton Recorder (CPR) and Marmap/Ecomon that can be used to add the information [54]. In future iterations of this assessment tool, it would be useful to develop normal ranges for other markers of nutrition such as vitamin and nutrient levels in the blood and feces.

In addition to the categories of health and behavior, we added a category for the collection of primary information such as individual ID number, sex, age or age class, date and time, and location of the sighting. The prototype of the NARW welfare assessment tool can be found in Tables 1 and 2.

Table 1. Prototype of the NARW welfare assessment Page 1. Total health and behavior scores are determined by adding numeric values of the corresponding section. Total Welfare Score is the combined Total Health Score and the Total Behavior Score. A negative score means negative welfare, 0 means neutral welfare, and a positive score means positive welfare. For a detailed description of the parameters used in the health assessment, please refer to Pettis et al., 2004 [22].

\begin{tabular}{|c|c|}
\hline & NARW Welfare Assessment \\
\hline Basic Information & $\begin{array}{c}\text { Individual ID\#: } \\
\text { Date and Time of Sighting (MM/DD/YYYY, 00:00): } \\
\text { Location of Sighting (latitude and longitude or area code): } \\
\text { Sex: MALE/FEMALE/UNKNOWN (circle one) } \\
\text { Age (or age class if unknown): }\end{array}$ \\
\hline \multirow{8}{*}{ Welfare Assessment } & Health \\
\hline & $\begin{array}{l}\text { Skin Condition: GOOD (0) vs. POOR }(-1) \\
\text { Rake Marks: FEW (0) vs. SEVERAL }(-1) \\
\text { Cyamids: NONE TO FEW (0) vs. MANY }(-1) \\
\text { Baleen Damaged: NO (1) vs. YES }(-1) \\
\text { Entangled: YES }(-1) \text { vs. NO }(0)\end{array}$ \\
\hline & Nutrition \\
\hline & $\begin{array}{l}\text { Body Condition: GOOD (1) vs. MODERATE (0) vs. POOR }(-1) \\
\text { Prey quality (energy content in J/C5): } \\
\left.\text { Prey abundance (in C5/m } \mathrm{m}^{3}\right) \text { : } \\
\text { Prey score: }>3 \mathrm{~kJ} / \mathrm{m}^{3}(1) \text { vs. } 3 \mathrm{~kJ} / \mathrm{m}^{3}(0) \text { vs. }<3 \mathrm{~kJ} / \mathrm{m}^{3}(-1)\end{array}$ \\
\hline & Behavior * \\
\hline & $\begin{array}{l}\text { Aggressive/Avoidance/Injured Score }(\text { each behavior }=-1) \text { : } \\
\text { Investigative/Neutral Score }(\text { each behavior }=0): \\
\text { Play/Feeding/Mating Score }(\text { each behavior }=1) \text { : }\end{array}$ \\
\hline & Welfare Score \\
\hline & $\begin{array}{l}\text { Total Score for Health: } \\
\text { Total Score for Nutrition: } \\
\text { Total Score for Behavior } \\
\text { Total Welfare Score: }\end{array}$ \\
\hline
\end{tabular}

* See Page 2 for list of behaviors comprising each of the following categories. 
Table 2. List of behaviors (Page 2) under each category of the NARW welfare assessment tool (positive behaviors, neutral behaviors and negative behaviors). Each observed behavior is recorded under the associated behavior category and contributes its corresponding value to the overall behavior score.

\begin{tabular}{|c|c|c|}
\hline \multicolumn{3}{|c|}{ Behavior } \\
\hline $\begin{array}{l}\text { Aggressive/Avoidance/Injured or Dead } \\
\qquad(-1)\end{array}$ & Investigative/Neutral (0) & Play/Feeding/Mating (1) \\
\hline Live stranded & Calf with another & Medical Intervention \\
\hline With predatory shark & Calf with unphotographed whale & Pregnant (if live) \\
\hline Aggressive vessel & Mom with unphotographed calf & Disentangled \\
\hline Avoidance to approaching platform & Gunshot & Disentanglement attempt \\
\hline Fluking (entangled whale) & Bubbles & Line gone \\
\hline Not fluking (entangled whale) & Curious Approach & Disentangled partially \\
\hline Reaction to sampling or platform & Defecation & Coordinated Feeding \\
\hline Sick whale & Head lift & Echelon Feeding \\
\hline Trapped in weir & Head push & Unspecified type of feeding \\
\hline Oil slicks & Head tilt & Surface or skim feeding \\
\hline Calf Alone & Human presence near a whale & Subsurface feeding \\
\hline & Linear travel & Mom cradling calf \\
\hline & Logging & Probable nursing \\
\hline & Mooing & Focal animal \\
\hline & Mouth open & Intromission \\
\hline & Mud & Surface Active Group \\
\hline & Posturing & Belly to Belly \\
\hline & Racing dive & Body contact \\
\hline & Random subsurface movement & Breaching \\
\hline & Shivering/Jell-o & Chin Breach \\
\hline & Spyhopping & Belly up \\
\hline & Underwater exhalation & Flippering/flipper slapping \\
\hline & Unusual behavior & Lobtailing \\
\hline & & Lunge \\
\hline & & Rolling \\
\hline & & Tail breach \\
\hline & & Play \\
\hline
\end{tabular}

\subsection{The Importance of a Welfare Tool}

This is the first attempt to develop a welfare assessment tool for the NARW and has identified some key areas where more information is needed and where future versions can improve. The importance of this tool relies on its ability to compile and communicate data concerning the NARW population in a way that is easily understood by diverse audiences. While much of the data needed to complete this assessment already exists, it is likely in different databases. This welfare tool will help collect that information to provide a more holistic view of how health, nutrition, and behavior interact to influence NARW welfare. Once the necessary data have been gathered and welfare scores calculated for NARW individuals, it will become easier to disseminate the findings to the public. The lack of action to conserve the NARWs is largely due to a complete lack of pressure from consumers. One of the main barriers to conservation of marine mammals, especially the NARW, is the lack of visibility. Moore and Van der Hoop (2012) summarize this issue well in the following quote: "Consider the likely difference in response if the results of long standing right whale entanglements (i.e., emaciation, starvation, chronic pain and infection) were observed on a daily basis by humans as they went about their lives in urban, suburban and rural communities rather than remaining out of sight at sea. If the equivalent fixed fishery traps and nets were to be set on land, with a comparably slow and painful death for wildlife, the responsible industry could be subject to consumer revolt, irrespective of whether there was an actual law concerning such an interaction" [8]. A welfare assessment specific for the NARW provides an enhanced ability to frame the plight of the NARW as a welfare concern. It also presents a different approach to conservation 
messaging and ultimately leads to greater public understanding and consumer pressure to take the necessary actions to save the NARWs from extinction.

\subsection{Next Steps}

Our suggested welfare assessment tool is designed for use by field biologists to measure NARW welfare in conjunction with other methods of quantifying stress as it relates to health, such as fecal, respiratory and baleen sample hormone profile analysis [1,24]. Interobserver reliability should be determined by providing standardized training and having different observers use the tool to evaluate the welfare of the same individual animal. This will help improve the applicability and accuracy of the tool. Once the tool has undergone testing and validation it will be used to measure NARW welfare in the field, without waiting for biological test results. This will allow for timely evaluation of individual welfare and will contribute to improved understanding of the NARW species status.

\section{Conclusions}

The increasing number of NARW serious injuries and deaths resulting from humaninduced causes is both a conservation concern and an animal welfare concern [9]. By reviewing the literature, we have identified appropriate frameworks for large whale welfare assessments. We developed a prototypic welfare assessment tool for NARWs. Once validated, this NARW welfare assessment tool can be used in conjunction with existing objective measures of health to integrate understanding of welfare and health in a critically endangered species.

Author Contributions: Conceptualization, K.K., L.C., H.P., P.C., F.N.; writing-original draft preparation, K.K.; writing-review and editing, M.J., K.M., F.N.; supervision, F.N.; funding acquisition, K.K., F.N. All authors have read and agreed to the published version of the manuscript.

Funding: The research was funded by The Edward Gorey Charitable Trust through Tufts Cummings School of Veterinary Medicine, grant number 020590852. The APC was waived for this article.

Institutional Review Board Statement: Not applicable.

Informed Consent Statement: Not applicable.

Data Availability Statement: Not applicable.

Conflicts of Interest: The funders had no role in the design of the study; in the collection, analyses, or interpretation of data; in the writing of the manuscript, or in the decision to publish the results.

\section{References}

1. Moore, M.J.; Rowles, T.K.; Fauquier, D.A.; Baker, J.D.; Biedron, I.; Durban, J.W.; Hamilton, P.K.; Henry, A.G.; Knowlton, A.R.; McLellan, W.A.; et al. Assessing North Atlantic right whale health: Threats, and development of tools critical for conservation of the species. Dis. Aquat. Org. 2021, 143, 205-226. [CrossRef]

2. Pace, R.M.; Corkeron, P.J.; Kraus, S.D. State-space mark-recapture estimates reveal a recent decline in abundance of North Atlantic right whales. Ecol. Evol. 2017, 7, 8730-8741. [CrossRef]

3. Pettis, H.M.; Pace, R.I.; Hamilton, P.K. North Atlantic Right Whale Consortium 2019 Annual Report Card; North Atlantic Right Whale Consortium: Boston, MA, USA, 2020.

4. Kraus, S.D.; Kenney, R.D.; Mayo, C.A.; McLellan, W.A.; Moore, M.J.; Nowacek, D.P. Recent Scientific Publications Cast Doubt on North Atlantic Right Whale Future. Front. Mar. Sci. 2016, 3, 137. [CrossRef]

5. Sharp, S.M.; McLellan, W.A.; Rotstein, D.S.; Costidis, A.M.; Barco, S.G.; Durham, K.; Pitchford, T.D.; Jackson, K.A.; Daoust, P.Y.; Wimmer, T.; et al. Gross and histopathologic diagnoses from north atlantic right whale eubalaena glacialis mortalities between 2003 and 2018. Dis. Aquat. Organ. 2019, 135, 1-31. [CrossRef] [PubMed]

6. Moore, M.J.; Bogomolni, A.; Bowman, R.; Hamilton, P.K.; Harry, C.T.; Knowlton, A.R.; Landry, S.; Rotstein, D.S.; Touhey, K. Fatally entangled right whales can die extremely slowly. In Proceedings of the Oceans 2006, Boston, MA, USA, 18-21 September 2006; pp. 1-3. [CrossRef]

7. Knowlton, A.R.; Hamilton, P.K.; Marx, M.K.; Pettis, H.M.; Kraus, S.D. Monitoring North Atlantic right whale Eubalaena glacialis entanglement rates: A 30 yr retrospective. Mar. Ecol. Prog. Ser. 2012, 466, 293-302. [CrossRef]

8. Moore, M.J.; van der Hoop, J.M. The painful side of trap and fixed net fisheries: Chronic entanglement of large whales. J. Mar. Biol. 2012, 2012, 1-4. [CrossRef] 
9. Moore, M.J. Food for thought: How we all kill whales. ICES J. Mar. Sci. 2014, 71, 760-763. [CrossRef]

10. Vanderlaan, A.S.M.; Taggart, C.T. Vessel collisions with whales: The probability of lethal injury based on vessel speed. Mar. Mammal Sci. 2007, 23, 144-156. [CrossRef]

11. Van der Hoop, J.M.; Vanderlaan, A.S.M.; Taggart, C.T. Absolute probability estimates of lethal vessel strikes to North Atlantic right whales in Roseway Basin, Scotian Shelf. Ecol. Appl. 2012, 22, 2021-2033. [CrossRef]

12. Pettis, H.M.; Pace, R.M., III; Hamilton, P.K. North Atlantic Right Whale Consortium 2020 Annual Report Card. Report to the North Atlantic Right Whale Consortium; North Atlantic Right Whale Consortium: Boston, MA, USA, 2021.

13. Campbell-Malone, R.; Barco, S.G.; Daoust, P.Y.; Knowlton, A.R.; McLellan, W.A.; Rotstein, D.S.; Moore, M.J. Gross and histologic evidence of sharp and blunt trauma in North Atlantic right whales (Eubalaena glacialis) killed by vessels. J. Zoo Wildl. Med. 2008, 39, 37-55. [CrossRef]

14. Hildebrand, J. Sources of anthropogenic sound in the marine environment. In Report to the Policy on Sound and Marine Mammals: An International Workshop; US Marine Mammal Commission and Joint Nature Conservation Committee: London, UK, 2004.

15. Parks, S.E.; Johnson, M.; Nowacek, D.; Tyack, P.L. Individual right whales call louder in increased environmental noise. Biol. Lett. 2011, 7, 33-35. [CrossRef]

16. Rolland, R.M.; Parks, S.E.; Hunt, K.E.; Castellote, M.; Corkeron, P.J.; Nowacek, D.P.; Wasser, S.K.; Kraus, S.D. Evidence that ship noise increases stress in right whales. Proc. R. Soc. B 2012, 279, 2363-2368. [CrossRef] [PubMed]

17. Reygondeau, G.; Beaugrand, G. Future climate-driven shifts in distribution of Calanus finmarchicus. Glob. Chang. Biol. 2011, 17, 756-766. [CrossRef]

18. Record, N.R.; Runge, J.A.; Pendleton, D.E.; Balch, W.M.; Davies, K.T.A.; Pershing, A.J.; Johnson, C.L.; Stamieszkin, K.; Ji, R.; Feng, Z.; et al. Rapid climate-driven circulation changes threaten conservation of endangered North Atlantic right whales. Oceanography 2019, 32, 162-169. [CrossRef]

19. Lehoux, C.; Plourde, S.; Lesage, V. Significance of Dominant Zooplankton Species to the North Atlantic Right Whale Potential Foraging Habitats in the Gulf of St. Lawrence: A Bio-Energetic Approach; DFO Canadian Science Advisory Secretariat Research Document 2020/033; Fisheries and Oceans Canada and Canadian Science Advisory Secretariat: Ottawa, ON, Canada, 2020; iv + 44 p.

20. Meyer-Gutbrod, E.L.; Greene, C.H.; Davises, K.T.A.; Johns, D.G. Ocean regime shift is driving collapse of the North Atlantic right whale population. Oceanography 2021, 34, 22-31. [CrossRef]

21. Hunt, K.E.; Moore, M.J.; Rolland, R.M.; Kellar, N.M.; Hall, A.J.; Kershaw, J.; Raverty, S.A.; Davis, C.E.; Yeates, L.C.; Fauquier, D.A.; et al. Overcoming the challenges of studying conservation physiology in large whales: A review of available methods. Conserv. Physiol. 2013, 1, cot006. [CrossRef]

22. Pettis, H.M.; Rolland, R.M.; Hamilton, P.K.; Brault, S.; Knowlton, A.R.; Kraus, S.D. Visual health assessment of North Atlantic right whales (Eubalaena glacialis) using photographs. Can. J. Zool. 2004, 82, 8-19. [CrossRef]

23. Stewart, J.D.; Durban, J.W.; Knowlton, A.R.; Lynn, M.S.; Fearnbach, H.; Barbaro, J.; Perryman, W.L.; Miller, C.A.; Moore, M.J. Decreasing body lengths in North Atlantic right whales. Current Biology. Curr. Biol. 2021, 31, 3174-3179. [CrossRef]

24. Hunt, K.E.; Lysiak, N.S.; Moore, M.; Rolland, R.M. Multi-year longitudinal profiles of cortisol and corticosterone recovered from baleen of North Atlantic right whales (Eubalaena glacialis). Gen. Comp. Endocrinol. 2017, 254, 50-59. [CrossRef]

25. Davis, G.E.; Baumgartner, M.F.; Bonnell, J.M.; Bell, J.; Berchok, C.; Thornton, J.B.; Brault, S.; Buchanan, G.; Charif, R.A.; Cholewiak, D.; et al. Long-term passive acoustic recordings track the changing distribution of North Atlantic right whales (Eubalaena glacialis) from 2004-2014. Sci. Rep. 2017, 7, 13460. [CrossRef]

26. Fraser, D. Toward a Synthesis of Conservation and Animal Welfare Science. Anim Welf. 2010, 19, 121-124.

27. Broom, D.M. A History of Animal Welfare Science. Acta Biotheor. 2011, 59, 121-137. [CrossRef]

28. Mellor, D.J. Updating animal welfare thinking: Moving beyond the "five freedoms" towards "A life worth living". Animals 2016, 6, 21. [CrossRef] [PubMed]

29. Mellor, D.J. Operational details of the five domains model and its key applications to the assessment and management of animal welfare. Animals 2017, 7, 60. [CrossRef]

30. Paquet, P.C.; Darimont, C. Wildlife conservation and animal welfare: Two sides of the same coin? Anim. Welf. 2010, 19, 177-190.

31. Papastavrou, V.; Leaper, R.; Lavigne, D. Why management decisions involving marine mammals should include animal welfare. Mar. Policy 2017, 79, 9-24. [CrossRef]

32. Beausoleil, N.J.; Mellor, D.J.; Baker, L.; Baker, S.E.; Bellio, M.; Clarke, A.S.; Dale, A.; Garlick, S.; Jones, B.; Harvey, A.; et al. "Feelings and fitness" Not "Feelings or fitness"-The Raison d'être of conservation welfare, which aligns conservation and animal welfare objectives. Vet. Sci. 2018, 5, 1-14. [CrossRef]

33. Robbins, M.M.; Gray, M.; Fawcett, K.A.; Nutter, F.B.; Uwingeli, P.; Mburanumwe, I.; Kagoda, E.; Basabose, A.; Stoinski, T.S.; Cranfield, M.R.; et al. Extreme conservation leads to the recovery of the Virunga mountain gorillas. PLoS ONE 2011, 6, e19788. [CrossRef] [PubMed]

34. Jordan, B. Science-based assessment of animal welfare: Wild and captive animals. Rev. Sci. Tech. Off. Int. Epiz. 2005, 24, 515-528. [CrossRef]

35. Romero, M.L.; Butler, L.K. Endocrinology of Stress. Int. J. Comp. Psychol. 2007, 20, 89-95.

36. Swaisgood, R.R. Current status and future directions of applied behavioral research for animal welfare and conservation. Appl. Anim. Behav. Sci. 2006, 102, 139-162. [CrossRef] 
37. Mellor, D.J.; Hunt, S. Caring for Wildlife: The World Zoo and Aquarium Animal Welfare Strategy; Gusset, M., Ed.; WAZA Executive Office: Gland, Switzerland, 2015; pp. 1-87.

38. Hill, S.P.; Broom, D.M. Measuring zoo animal welfare: Theory and practice. Zoo Biol. 2009, 28, 531-544. [CrossRef] [PubMed]

39. Kagan, R.; Carter, S.; Allard, S. A Universal Animal Welfare Framework for Zoos. J. Appl. Anim. Welf. Sci. 2015, 18, S1-S10. [CrossRef] [PubMed]

40. Sherwen, S.L.; Hemsworth, L.M.; Beausoleil, N.J.; Embury, A.; Mellor, D.J. An animal welfare risk assessment process for zoos. Animals 2018, 8, 130. [CrossRef]

41. Whitham, J.C.; Wielebnowski, N. Animal-Based welfare monitoring: Using keeper ratings as an assessment tool. Zoo Biol. 2009, 28, 545-560. [CrossRef] [PubMed]

42. Justice, W.S.M.; O’brien, M.F.; Szyszka, O.; Shotton, J.; Gilmour, J.E.M.; Riordan, P.; Wolfensohn, S. Adaptation of the animal welfare assessment grid (AWAG) for monitoring animal welfare in zoological collections. Vet. Rec. 2017, 181, 143. [CrossRef]

43. Ryan, M.; Waters, R.; Wolfensohn, S. Assessment of the Welfare of Experimental Cattle and Pigs Using the Animal Welfare Assessment Grid. Animals 2021, 11, 999. [CrossRef]

44. Wolfensohn, S.; Sharpe, S.; Hall, I.; Lawrence, S.; Kitchen, S.; Dennis, M. Refinement of welfare through development of a quantitative system for assessment of lifetime experience. Anim. Welf. 2015, 24, 139-149. [CrossRef]

45. Brakes, P. Sociality and Wild Animal Welfare: Future Directions. Front. Vet. Sci. 2019, 6, 62. [CrossRef]

46. Harvey, A.M.; Beausoleil, N.J.; Ramp, D.; Mellor, D.J. A Ten-Stage Protocol for Assessing the Welfare of Individual Non-Captive Wild Animals: Free-Roaming Horses (Equus Ferus Caballus) as an Example. Animals 2021, 10, 148. [CrossRef]

47. Clegg, I.L.K.; Borger-Turner, J.L.; Eskelinen, H.C. C-Well: The development of a welfare assessment index for captive bottlenose dolphins (Tursiops truncatus). Anim. Welf. 2015, 24, 267-282. [CrossRef]

48. Nicol, C.; Bejder, L.; Green, L.; Johnson, C.; Keeling, L.; Noren, D.; Van der Hoop, J.; Simmonds, M. Anthropogenic Threats to Wild Cetacean Welfare and a Tool to Inform Policy in This Area. Front Vet. Sci. 2020, 7, 57. [CrossRef]

49. Butterworth, A. Report of the Workshop to Support the IWC'S Consideration of Non-Hunting Related Aspects of Cetacean Welfare. Kruger National Park, South Africa, 3-4 May 2016; International Whaling Commission: Cambridge, UK, 2016.

50. Zani, M.; Hamilton, P. North Atlantic Right Whale Consortium Photographic Database/Catalog Submission; North Atlantic Right Whale Consortium: Boston, MA, USA, 2018.

51. Baumgartner, M. Comparison of Calanus finmarchicus fifth copepodite abundance estimates from nets and an optical plankton counter. J. Plankton Res. 2003, 25, 855-868. [CrossRef]

52. McKinstry, C.A.E.; Westgate, A.J.; Koopman, H.N. Annual variation in the nutritional value of stage V Calanus finmarchicus: Implications for right whales and other copepod predators. Endanger. Species Res. 2013, 20, 195-204. [CrossRef]

53. Michaud, J.; Taggart, C.T. Lipid and gross energy content of North Atlantic right whale food, Calanus finmarchicus, in the Bay of Fundy. Endanger. Species Res. 2007, 3, 77-94. [CrossRef]

54. Pershing, A.J.; Record, N.R.; Monger, B.C.; Pendleton, D.E.; Woodard, L.A. Model-based estimates of Calanus finmarchicus abundance in the Gulf of Maine. Mar. Ecol. Prog. Ser. 2009, 378, 227-243. [CrossRef] 